\title{
Instantaneous Light Measurements Predict Relative Cumulative Light Levels within an Apple Canopy
}

\author{
Richard J. Campbell' and Richard P. Marini \\ Department of Horticulture, Virginia Polytechnic Institute and State University, Blacksburg, \\ VA 24061 \\ Additional index words. Malus domestica, photosynthetic photon flux density, quantum sensor, sunflecks
}

\begin{abstract}
Percent instantaneous incident photosynthetic photon flux density (\% INPPFD) was measured within an apple (Malus domestica Borkh.) canopy for various sky conditions and used to predict the percent cumulative incident photosynthetic photon density (PPD) for the last 10 weeks of the growing season $\left(\% \mathrm{CPPD}_{\mathrm{L} s}\right)$ and the total growing season $\left(\% \mathrm{CPPD}_{\mathrm{TS}}\right)$. Instantaneous measurements from overcast conditions were superior to measurements from clear or hazy conditions for the prediction of $\% \mathrm{CPPD}_{\mathrm{LS}}$ in 1989 and 1990. A one-to-one relationship between \% INPPFD and $\% \mathrm{CPPD}_{\mathrm{LS}}$ was found for overcast conditions in both years, even though there was an $11 \%$ difference in total cumulative PPD between the years. The models had good predictive accuracy, with prediction coefficients of determination $\left(R_{\text {Pred }}^{2}\right)>0.83$ in both years $(n=30)$. \% INPPFD from overcast conditions also yielded accurate predictive models for $\% \mathrm{CPPD}_{\mathrm{Ts}}\left(R_{\text {Pred }}^{2}>\mathbf{0 . 8 4}, \mathrm{n}=30\right.$ ), which differed from the models for $\% \mathrm{CPPD}_{\mathrm{Ls}}$. Predictive models (for both \%CPPD ${ }_{\mathrm{LS}}$ and \%CPPD $\mathrm{Ts}$ ) from \% INPPFD made before the canopy was fully developed differed from the models developed after canopy development was complete. The models still had good predictive accuracy, with $R^{2}{ }_{\text {pred }}>0.76$ $(n=30)$. Predictive models developed for cloudless conditions had inferior predictive accuracy $\left(R_{\text {Pred }}^{2}=0.49\right.$ to $0.80, \mathrm{n}=30$ ) compared to models for overcast conditions. $R^{2}{ }_{\text {Pred }}$ were higher for hazy than for clear conditions. Time of day (1000 to $1400 \mathrm{HR}$ ) had no consistent effect on the development of predictive models for any weather condition. The most reliable models resulted from the average of several measurements within a day, particularly for cloudless conditions.
\end{abstract}

Many instruments and measurement techniques have been used to characterize the light environment of plant communities and individual tree canopies (Anderson, 1964a; Jackson, 1980). The introduction of the quantum sensor allowed for the relatively quick and simple selective measurement of the photosynthetically active waveband 400 to $700 \mathrm{~nm}$, expressed as a photosynthetic photon flux density (PPFD). Instantaneous measurements with quantum sensors (and other instruments) have been used extensively for light environment studies within apple tree canopies and have been related to spur, leaf, and fruit quality characteristics within the canopy (Barritt et al., 1987; Marini and Barden, 1982; Marini and Marini, 1983; Morgan et al., 1984; Patten and Proebsting, 1986). Instantaneous light measurements, often based on only a few measurements during the season, have been used to represent total seasonal (cumulative) light levels. The validity of instantaneous measurements as estimates of total cumulative light levels has been questioned due to the complicated nature of canopy/light interactions, such as weather variations, proportions of direct and diffuse light, sunflecks, spectral changes, and the timing of measurements (Anderson, 1964a; Monselise, 1951).

For the measurement of PPFD, Grappadelli and Coston (1988) described the construction of an inexpensive silicon photocell sensor that had a similar measurement response to commercially produced quantum sensors. Combined with a datalogger, these sensors provide an affordable method of measuring the total cumulative photosynthetic photon density (PPD) impinging on

Received for publication 21 May 1991. Accepted for publication 11 Mar 1992. The cost of publishing this paper was defrayed in part by the payment of page charges. Under postal regulations, this paper therefore must be hereby marked advertisement solely to indicate this fact.

'To whom all correspondence and reprint requests should be addressed. Present address: Research Center, Fairchild Tropical Garden, 11935 Old Cutler Rd, Miami, FL 33156. several canopy positions throughout the season and provide an opportunity to relate these total cumulative PPD values to predicted cumulative PPD values derived from instantaneous measurements.

The objectives of this study were to test the validity of instantaneous measurements as predictors of total cumulative PPD and to determine what sky conditions and measurement techniques yield the most reliable estimates.

\section{Materials and Methods}

Sensor construction and calibration. Silicon photocell sensors were constructed according to the design of Grappadelli and Coston (1988). The sensor body consisted of a clear plexiglass base with a $13 \times 32 \times 4-\mathrm{mm}$ depression routed-out for the placement of a $1 \times 2-\mathrm{cm}$ silicon photocell (Texas Optoelectronics, Garland, Texas) and a glass filter that excluded wavelengths $<400$ and $>700 \mathrm{~nm}$ (B638, Schott Optical Glass, Duryea, Pa.). Plasti-tak (Brooks Manufacturing, Cincinnati) secured the sensor and filter firmly in the depression. A lucite-L cast acrylic top (E.I. Du Pont De Nemours, Wilmington, Del.) was then glued to the base covering the filter and sensor and sealed with silicon rubber. The cast acrylic top (diffusive material) provided some degree of "cosine" correction. The entire sensor was covered with plastic electrician's tape except for a $1 \times 2-\mathrm{cm}$ window directly above the filter and silicon photocell, allowing light to enter. Eight meters of 24-gauge coated wire was soldered to the sensor leads, and a 100-ohm, 20-turn trimmer potentiometer was spliced into the wire for standardization of sensor output. The sensors were connected to a $21 \mathrm{X}$ data logger (Campbell Scientific, Logan, Utah) through a 32-channel multiplexer (Model AM32, Campbell Scientific). The sensors were standardized against a Lambda quantum sensor (Model LI190SB, LI-COR, Lincoln, Neb.) on a cloudless day by adjusting the potentiometer until the millivolt output was equal to the 
output of the quantum sensor. Sensors were then compared to the quantum sensor over a range of light levels to ensure a linear response.

Orchard. The study was conducted in 1989 and 1990 at the Virginia Polytechnic Institute and State Univ. Horticulture Farm in Blacksburg $\left(\approx 38^{\circ} \mathrm{N}\right)$. The trees used were 14-year-old 'Red Prince Delicious'/MM.111, averaging $5.4 \mathrm{~m}$ high and $4.8 \mathrm{~m}$ wide and with an average trunk circumference of $60 \mathrm{~cm}$. The east-west rows were spaced at $5.5 \mathrm{~m}$ in-row and $6.1 \mathrm{~m}$ between rows.

Sensor placement. Twenty-three silicon photocell sensors were placed within one of the 'Delicious' trees in 1989, and 15 sensors were placed in each of the two trees (30 total sensors) in 1990. The silicon photocell sensors were placed in close proximity to fruiting spurs within the canopy for use in another study. Sensor (canopy) positions were chosen to provide a wide range of light levels. The sensors were attached with electrician's tape to $1.9 \times 3.8-\mathrm{cm}$ wooden strips that were nailed at varying heights to $4.6-\mathrm{m}$-high, $5 \times 10-\mathrm{cm}$ wooden boards (three to five sensors per board). Five boards were placed within the canopy of each tree, one immediately adjacent to the trunk and the remaining four in either the NE, NW, SE, or SW quadrants of the tree, $\approx 50$ to $100 \mathrm{~cm}$ from the periphery of the canopy. The sensors were leveled and periodically adjusted to ensure they remained horizontal. The sensors were oriented to the southern side of the boards to prevent direct shading of sensors from the boards themselves. For incident PPFD measurements and comparison of the two sensor types, one silicon photocell sensor and one Lambda quantum sensor were placed side-byside on a $4.6-\mathrm{m}$ pole in the row where two trees had been removed.

Cumulative light measurements. The datalogger was programmed to record the PPFD at each sensor position at 10-sec intervals from 0600 to $2100 \mathrm{HR}$. These data were stored as 5min PPD totals in 1989 and as 15-min PPD totals in 1990 and expressed in quantum units, millimoles per square meter. The data were transferred to a computer and summed for cumulative PPD totals with SAS (SAS, 1985). Percent cumulative incident PPD was calculated by dividing the cumulative total PPD for each position by the cumulative total incident PPD. PPD was recorded from 22 July to 4 Oct. 1989 and termed percent cumulative incident late-season PPD $\left(\% \mathrm{CPPD}_{\mathrm{LS}}\right)$. PPD was measured from 23 Mar. to 4 Oct. 1990 and the percent cumulative incident total-season PPD (\% $\left.\mathrm{CPPD}_{\mathrm{TS}}\right)$ was calculated. A second data set with $\%$ CPPD $_{L S}$ was also calculated for 1990 over the same dates used in the previous year.

Instantaneous light measurements. Instantaneous measurements were made on overcast and cloudless days. Cloudless days were differentiated into clear and hazy days in 1990 based on the average amount of diffuse PPFD available on that day; clear days had an average of $<300 \mathrm{~mol} \cdot \mathrm{s}^{-1} \cdot \mathrm{m}^{-2}$ diffuse PPFD, and hazy days had 500 to $700 \mathrm{~mol} \cdot \mathrm{s}^{-1} \cdot \mathrm{m}^{-2}$ of diffuse PPFD. Diffuse PPFD was measured by shading the incident sensor with a $10-\mathrm{cm}^{2}$ disk (placed $\approx 1 \mathrm{~m}$ above the sensor) to block the direct rays of light. Instantaneous PPFD measurements were made hourly between 1000 and 1400 HR on three overcast and three hazy days in 1989 by keying through all 23 channels of the datalogger and recording the PPFD level at that instant. Each series of instantaneous measurements was completed in <60 sec. Incident PPFD, recorded at each hourly measurement, was used to calculate percent instantaneous incident PPFD values (\%INPPFD). In 1990, \%INPPFD were recorded hourly between 1100 and $1400 \mathrm{HR}$ with the silicon photocell sensors at all 30 positions within the two trees on two clear, two hazy, and six overcast days. Each series of measurements was completed in $<90 \mathrm{sec}$. \%INPPFD were also measured at 20 of the 30 total sensor positions (selected to provide a range of light levels) on each measurement day in 1990 with a Lambda quantum sensor by holding the sensor in a horizontal position directly above the silicon photocell sensor. These measurements were completed in $\leq 5 \mathrm{~min}$.

Statistical analysis (model development). Hourly \%INPPFD were averaged for each measurement day and regressed against \% CPPD ${ }_{\mathrm{LS}}$ in 1989 and 1990, and against \%CPPD $\mathrm{TS}$ in 1990. Regression models for \%INPPFD and $\% \mathrm{CPPD}_{\mathrm{LS}}$ were also developed for the individual hourly measurements within each day to determine what time of the day (if any) yielded the best model. Pooled models were also developed based on all data (multiple measurement days) for each particular weather condition within each year. Both fitting criteria $\left(R_{\text {Fit }}^{2}\right)$, and prediction criteria $\left(R_{\text {Pred }}^{2}\right)$ are presented for each predictive model. The $R_{\text {Pred }}^{2}$ is calculated from the prediction error sum of squares, which is considered a form of data-splitting (Montgomery and Peck, 1982). This statistic provides an indication of the predictive accuracy of a given model. Models were compared among days within each year and between years with indicator variables in multiple regression (Montgomery and Peck, 1982). Models were judged to be statistically different if either the slope or the intercept differed at $P=0.05$.

\section{Results}

Cumulative late-season PPD, overcast conditions. Predictive models for \%oCPPD ${ }_{\mathrm{LS}}$ developed from \%INPPFD during overcast conditions in 1989 fit the data better $\left(R_{\mathrm{Fit}}^{2}\right)$ and had superior predictive accuracy $\left(R_{\text {Pred }}^{2}\right)$ than models developed for hazy conditions (Table 1). The models for the overcast conditions were equivalent among all 3 days tested, with similar degrees of predictive accuracy. There was nearly a one-to-one relationship (intercept $=2$ to 4 , and slope $=0.95$ to 0.98 ) between $\%$ INPPFD and $\% \mathrm{CPPD}_{\mathrm{LS}}$ for each individual day and for the pooled model for overcast conditions. Predictive models for \%CPPD ${ }_{1 S}$ developed for overcast conditions after 15 June 1990 were equivalent to the models developed in 1989; again, there was nearly a one-to-one relationship (intercept $=0$ to 2 , and slope $=1.0$ to 1.04 ) between \%INPPFD and $\% \mathrm{CPPD}_{\mathrm{LS}}$ (Table 2 ). The predictive models were equivalent for the overcast days

Table 1. Predictive models for the relationship between percent instantaneous incident PPFD measurements (\%INPPFD) and percent cumulative incident PPD measurements for the latter part of the season $\left(\% \mathrm{CPPD}_{\mathrm{LS}}\right), 22$ July -4 Oct. 1989. Model: $\% \mathrm{CPPD}_{\mathrm{LS}}=$ $\mathrm{a}+\mathrm{b}(\%$ INPPFD $)$.

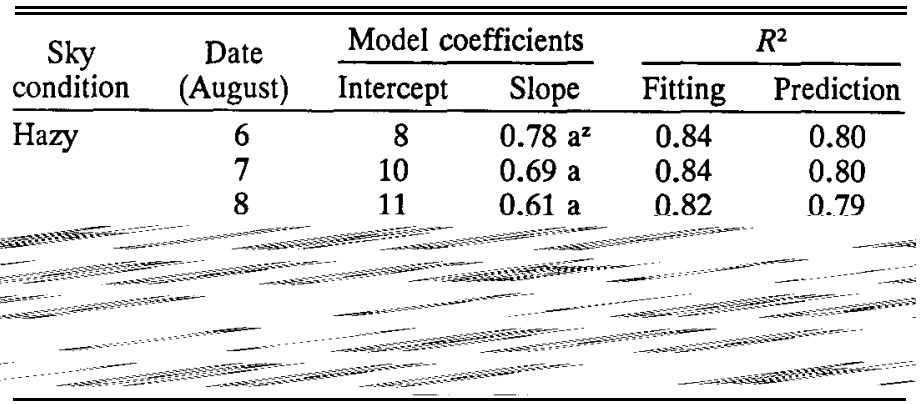

${ }^{\mathrm{z}}$ Models were compared with indicator variables and considered different if the slopes differed. Models followed by the same letter do not differ at $P<0.05(\mathrm{n}=30)$. All slopes differed from zero at $P<$ 0.01 . 
Table 2. Predictive models for the relationship between percent instantaneous incident PPFD measurements (\%INPPFD) and percent cumulative incident PPD measurements for the latter part of the season $\left(\% \mathrm{CPPD}_{\mathrm{LS}}\right), 22$ July -4 Oct. 1990. Model: $\% \mathrm{CPPD}_{\mathrm{LS}}=$ $\mathrm{a}+\mathrm{b}(\%$ INPPFD $)$.

\begin{tabular}{|c|c|c|c|c|c|}
\hline \multirow{2}{*}{$\begin{array}{c}\text { Sky } \\
\text { conditions }\end{array}$} & \multirow[b]{2}{*}{ Date } & \multicolumn{2}{|c|}{ Model coefficients } & \multicolumn{2}{|c|}{$R^{2}$} \\
\hline & & Intercept & Slope & Fitting & Prediction \\
\hline \multirow[t]{3}{*}{ Clear } & 7 May & 14 & $0.53 \mathrm{a}^{2}$ & 0.57 & 0.51 \\
\hline & 7 Aug. & 14 & $0.52 \mathrm{a}$ & 0.54 & 0.49 \\
\hline & Pooled & 14 & $0.52 \mathrm{a}$ & 0.56 & 0.53 \\
\hline \multirow[t]{3}{*}{ Hazy } & 12 June & 10 & $0.79 \mathrm{a}$ & 0.75 & 0.74 \\
\hline & 10 July & 8 & $0.78 \mathrm{a}$ & 0.81 & 0.80 \\
\hline & Pooled & 9 & $0.78 \mathrm{a}$ & 0.79 & 0.76 \\
\hline \multirow[t]{6}{*}{ Overcast } & $30 \mathrm{Mar}$. & -116 & $1.83 \mathrm{~b}$ & 0.79 & 0.76 \\
\hline & 30 Apr. & -19 & $1.17 \mathrm{c}$ & 0.83 & 0.80 \\
\hline & 15 June & 2 & $1.04 \mathrm{~d}$ & 0.85 & 0.83 \\
\hline & 8 Aug. & 0 & $1.03 \mathrm{~d}$ & 0.90 & 0.89 \\
\hline & 22 Aug. & 1 & $1.00 \mathrm{~d}$ & 0.90 & 0.88 \\
\hline & Pooledy & 1 & $1.01 \mathrm{~d}$ & 0.90 & 0.89 \\
\hline
\end{tabular}

${ }^{\mathrm{z}}$ Models were compared with indicator variables and were considered different if the slopes differed. Models followed by the same letter do not differ at $P<0.05(\mathrm{n}=30)$. All slopes differed from zero at $P<$ 0.01 .

Pooled model based on 15 June, 8 Aug., and 22 Aug data only.

from 15 June-22 Aug. 1990. The actual \%INPPFD data for a typical overcast day in 1990 closely fit the pooled predictive model over the entire range of measured PPFD levels (Fig. 1a).

Predictive models developed from \%INPPFD for overcast conditions early in the season (before 15 June) differed from the models that were developed on the days later in the season (Table 2). The model for 30 Mar. had an intercept of - $116 \%$ and a slope of 1.83 , but the model still had a relatively good predictive value $\left(R_{\text {Pred }}^{2}=0.76\right)$. The highly negative intercept and slope $>1$ indicate that the model accounted for the higher light levels within the canopy when the trees were at the green= tip developmental stage. Since the canopy was still not fully developed by 30 Apr., the predictive model for $\% \mathrm{CPPD}_{\mathrm{LS}}$ still had a negative intercept and a slope $>1$, but the model was more similar to the models developed after the canopy was fully developed. Predictive models and data points for measurements from 30 Mar., 30 Apr., and 8 Aug. 1990 for overcast conditions are presented in Fig. 2.

Cumulative late-season PPD, cloudless conditions. The predictive models developed for hazy conditions differed from the models developed for overcast conditions in both 1989 and 1990 (Tables 1 and 2). The predictive models were equivalent among the hazy days within both years, with similar degrees of accuracy. The predictive models were also equivalent between the 2 years (pooled models). Models for the hazy conditions had a poorer fit to the data and predictive capability than the models for the overcast conditions, but $R_{\text {Pred }}^{2}$ was still nearly $80 \%$ in most cases. The variation around the regression line was clearly greater for hazy conditions (Fig. 1b) than for overcast conditions (Fig. 1a). Predictive models developed for clear conditions were statistically equivalent to the models developed for hazy conditions, but the models developed for clear conditions had poorer fitting and prediction criteria than the other models $\left(R_{\text {Pred }}^{2} \approx\right.$ $0.50)$. The large variation around the predicted line for clear days is evident in Fig. 1c.

Cumulative total-season PPD. The previous results concerned using \%INPPFD measurements to predict $\% \mathrm{CPPD}_{\mathrm{LS}}$, or the total cumulative light over the last 10 weeks of the season.

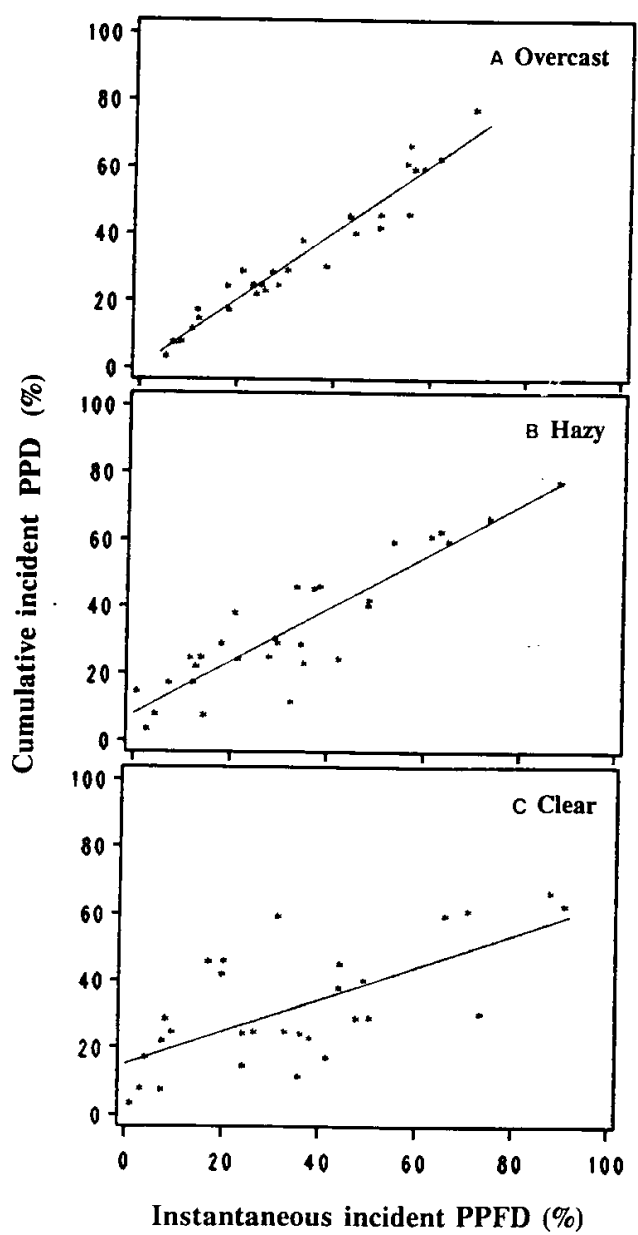

Fig. 1. Relationship between percent cumulative incident PPD and percent instantaneous incident PPFD for three sky conditions $(\mathrm{n}=$ 30). (A) Plotted data for 8 Aug. (overcast) and pooled regression model for overcast conditions, 1990: $\% \mathrm{CPPD}_{\mathrm{LS}}=1+1.01$ (\%INPPFD), $R^{2}=0.90$. (B) Plotted data for 10 July (hazy) and pooled model for hazy conditions, 1990: $\% \mathrm{CPPD}_{\mathrm{LS}}=9+0.78$ (\%INPPFD), $R^{2}=0.76$. (C) Plotted data for 7 Aug. (clear) and pooled regression model for clear conditions, 1990: \%CPPD ${ }_{\mathrm{LS}}=$ $14+0.52$ (\%INPPFD), $R^{2}=0.53$.

Such estimates of total light over this period could be useful for correlating light with fruit quality characteristics, such as red pigment development (Barritt et al., 1987; Lakso, 1980; Seeley et al., 1980). However, it may also be of interest to use \%INPPFD to predict $\% \mathrm{CPPD}_{\mathrm{T}}$, or cumulative light over the entire growing season. The predictive models for $\% \mathrm{CPPD}_{\mathrm{TS}}$ differed from the models for $\% \mathrm{CPPD}_{\mathrm{LS}}$ (Table 3 ), but the models had the same separation trend over the season. In general, the predictive models for $\% \mathrm{CPPD}_{\mathrm{TS}}$ had similar $R_{\mathrm{Fit}}^{2}$ and $R_{\text {Pred }}^{2}$ to those for the $\% \mathrm{CPPD}_{\mathrm{LS}}$ predictive models. After the canopy was fully developed (after 15 June), the intercept was $\approx 13$ and the slope 0.80 . Models developed to estimate total-season cumulative PPD values differed from models for late-season cumulative PPD values because \%INPPFD were measured when the canopy was fully developed and light levels within the canopy were low, but the interior positions had accumulated significant PPD before the canopy was fully developed. Therefore, the intercept should not have approached 0. \%INPPFD measured at the greentip developmental stage (30 Mar.) and a month later (30 Apr.) gave reliable estimates of total-season light levels and had better predictive value for $\% \mathrm{CPPD}_{\mathrm{TS}}$ than they had for $\% \mathrm{CPPD}_{\mathrm{LS}}$, 


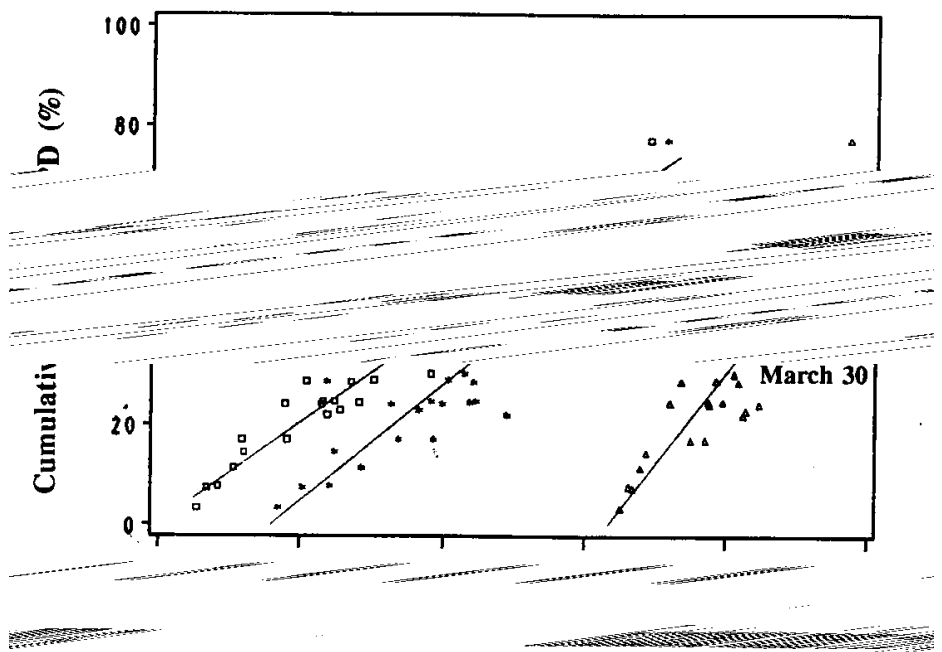

Fig. 2. Relationship between percent cumulative incident $\mathrm{PPD}_{\mathrm{IS}}$ and percent instantaneous incident PPFD for three overcast days in 1990: 30 Mar. $(\Delta), \% \mathrm{CPPD}_{\mathrm{LS}}=-116+1.83$ (\% INPPFD), $R^{2}=0.79$; 30 Apr. (*), \% CPPD LS $=-19+1.17$ (\% INPPFD), $R^{2}=0.83$; 8 Aug. (ㅁ), \%CPPD LS $=0+1.03$ (\%INPPFD), $R^{2}=0.90$.

Table 3. Predictive models for the relationship between percent instantaneous incident PPFD measurements (\%INPPFD) and percent cumulative incident PPD measurements for the entire season (\% $\mathrm{CPPD}_{\mathrm{TS}}$ ), 23 Mar.-2 Oct. 1990. Model: $\% \mathrm{CPPD}_{\mathrm{TS}}=\mathrm{a}+\mathrm{b}$ (\%INPPFD).

\begin{tabular}{lcccccc}
\hline \hline \multirow{2}{*}{$\begin{array}{c}\text { Sky } \\
\text { conditions }\end{array}$} & Date & \multicolumn{2}{c}{ Model coefficients } & & \multicolumn{2}{c}{$R^{2}$} \\
\cline { 3 - 4 } \cline { 5 - 6 } \cline { 5 - 6 } Clear & Intercept & Slope & & Fitting & Prediction \\
& 7 May & 22 & $0.45 \mathrm{a}^{\mathbf{z}}$ & & 0.63 & 0.58 \\
& 7 Aug. & 24 & $0.41 \mathrm{a}$ & & 0.50 & 0.44 \\
Hazy & Pooled & 23 & $0.43 \mathrm{a}$ & & 0.56 & 0.54 \\
& 12 June & 19 & $0.65 \mathrm{a}$ & & 0.79 & 0.74 \\
& 10 July & 18 & $0.65 \mathrm{a}$ & & 0.84 & 0.81 \\
Overcast & Pooled & 19 & $0.65 \mathrm{a}$ & & 0.76 & 0.75 \\
& 30 Mar. & -87 & $1.55 \mathrm{~b}$ & & 0.86 & 0.83 \\
& 30 Apr. & -5 & $0.99 \mathrm{c}$ & 0.89 & 0.88 \\
& 15 June & 13 & $0.88 \mathrm{~d}$ & 0.91 & 0.90 \\
& 8 Aug. & 13 & $0.83 \mathrm{~d}$ & 0.86 & 0.84 \\
& 22 Aug. & 13 & $0.80 \mathrm{~d}$ & & 0.86 & 0.84 \\
& Pooledy & 13 & $0.81 \mathrm{~d}$ & 0.86 & 0.86 \\
\hline \hline
\end{tabular}

${ }^{\mathrm{z}}$ Models were compared with indicator variables and were considered different if the slopes differed. Models followed by the same letter do not differ at $P<0.05(\mathrm{n}=30)$. All slopes differed from zero at $P<$ 0.01 .

'Pooled model for 15 June, 8 Aug., and 22 Aug. data only.

probably because they more accurately accounted for the early season light.

Time of day. For hazy conditions, the models developed between \%INPPFD and \%CPPD (LS or TS) for each measurement time within a day varied in predictive value, with no time between 1000 and $1400 \mathrm{HR}$ clearly superior for the prediction of $\% \mathrm{CPPD}_{\mathrm{LS}}$ (Table 4$)$. Within a hazy day, there were both strong and weak relationships, with $R_{\text {Fit }}^{2}$ ranging from $17 \%$ to $86 \%$. There was an improvement in the $R_{\text {Fit }}^{2}$, for hazy conditions when the measurement times were averaged (pooled model). For overcast conditions, there was typically little variation in $R_{\text {Fit }}^{2}$ throughout the day; all times between 1000 and 1400 HR yielded equivalent models with similar degrees of accuracy (Table 4). Averaging of repeated measurements during an individual day was therefore not as important on overcast days.
Table 4. Typical variation in the coefficients of determination for regression models between percent instantaneous incident PPFD (\%INPPFD) and percent cumulative incident late-season PPD $\left(\% \mathrm{CPPD}_{\mathrm{LS}}\right)$ for different measurement times within a hazy and an overcast day in 1989.

\begin{tabular}{lcc}
\hline \hline $\begin{array}{l}\text { Sky condition } \\
\text { and date }\end{array}$ & HR & $R_{\text {Fit }}^{2}$ \\
\hline Hazy, 8 Aug. & 1000 & 0.76 \\
& 1100 & 0.71 \\
& 1200 & 0.17 \\
& 1300 & 0.86 \\
Pooled & 1400 & 0.72 \\
Overcast, 25 Aug. & --- & 0.89 \\
& 1000 & 0.96 \\
& 1100 & 0.96 \\
& 1200 & 0.96 \\
Pooled & 1300 & 0.96 \\
\hline
\end{tabular}

Light distribution patterns within the canopy. Sunflecks were responsible for the variation in the predictive accuracy of the models developed for the multiple measurement times within an individual clear or hazy day. Figure 3 demonstrates the pattern of 15-min PPD accumulations over the course of a clear (13 Aug.) and an overcast day (28 Sept.) for selected canopy positions within a single 'Delicious' tree. The peripheral $(40 \mathrm{~cm}$ from top of tree), intermediate (250 cm from top), and interior (480 $\mathrm{cm}$ from top) canopy positions were located from the top to the bottom of the board adjacent to the trunk of a single tree (within $40 \mathrm{~cm}$ of trunk). Ambient PPD totals differed between the overcast and clear days, with a greater variation in the totals on the overcast day. Greater variation due to haze and highaltitude cirrus clouds would usually be present for cloudless conditions in Blacksburg, but this uniformly clear day was presented to provide a smooth baseline to illustrate sunflecks. At a peripheral canopy position, PPD totals on the clear day varied significantly due to shading within the canopy, as previously demonstrated (Christopher, 1934; Kromenko, 1972; Proctor et al., 1975); PPD totals for overcast conditions at the peripheral canopy position were lower than ambient, but the variation was similar to ambient because of the influence of diffuse light. At the intermediate canopy position there was much variation associated with the PPD totals on the clear day, while the PPD totals on the overcast day were low but relatively stable. At the interior canopy position, there was little PPD present on either the clear or overcast days, except for an occasional sunfleck on the clear day. These plots demonstrate how sunflecks influence instantaneous measurements for clear conditions and why averaging the measurements within a day is advantageous. For overcast conditions there were no sunflecks; therefore, averaging the measurement times within a day had little effect.

Silicon photocell and quantum sensor. All predictive models presented in this study are based on measurements with silicon photocell sensors. Predictive models were also developed with a commercially produced, hand-held Lambda quantum sensor. In all situations, the quantum sensor yielded equivalent models to the models developed with the silicon photocell sensors (Fig. 4 ), and, as with the silicon photocell sensor, overcast conditions yielded better predictive models than hazy or clear conditions. Prediction criteria for these models were usually similar to those for the silicon photocell sensors. However, because it took more time to complete a series of instantaneous measurements with 


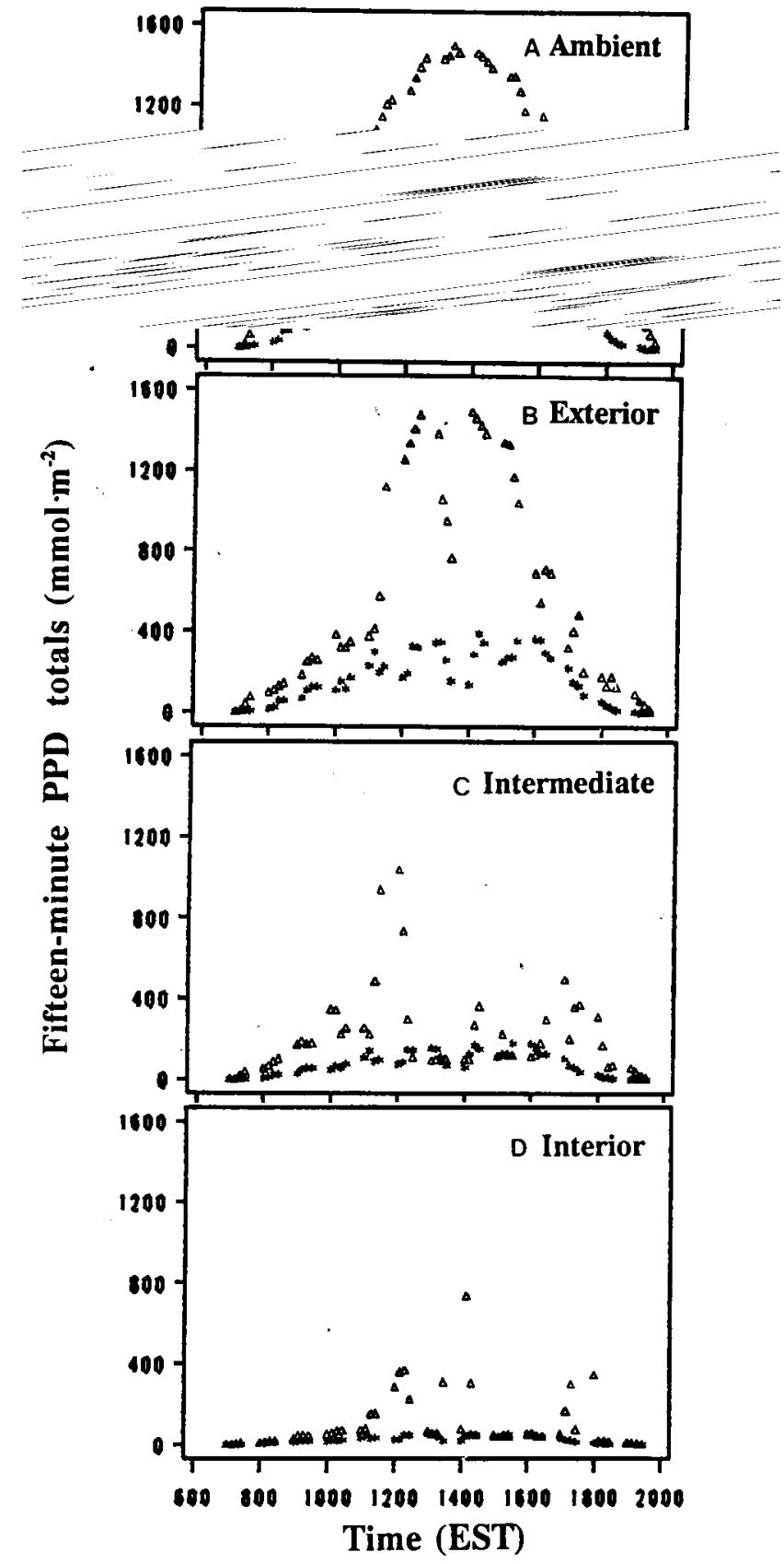

Fig. 3. Fifteen-minute PPD totals for selected sensor positions on a clear day $(\Delta), 9$ Aug., and an overcast day (*), 15 Aug. 1990. (A) Incident position; (B) exterior position; (C) intermediate position; (D) interior position.

the quantum sensor, the predictive models were sometimes weaker (lower $R_{\text {Pred }}^{2}$ ) when the light conditions were changing rapidly during measurements.

\section{Discussion}

Biggs et al. (1971) demonstrated that significant error could occur when a flat diffusive plexiglass surface was used to measure light at angles $>30^{\circ}$ from the vertical (cosine response), and Grappadelli and Coston (1988) discussed this as a potential problem with their design of a silicon photocell sensor. For our field conditions, however, the error induced by solar angle had little effect on the relationship between the silicon photocell sensor and the quantum sensor. There was some evidence of a

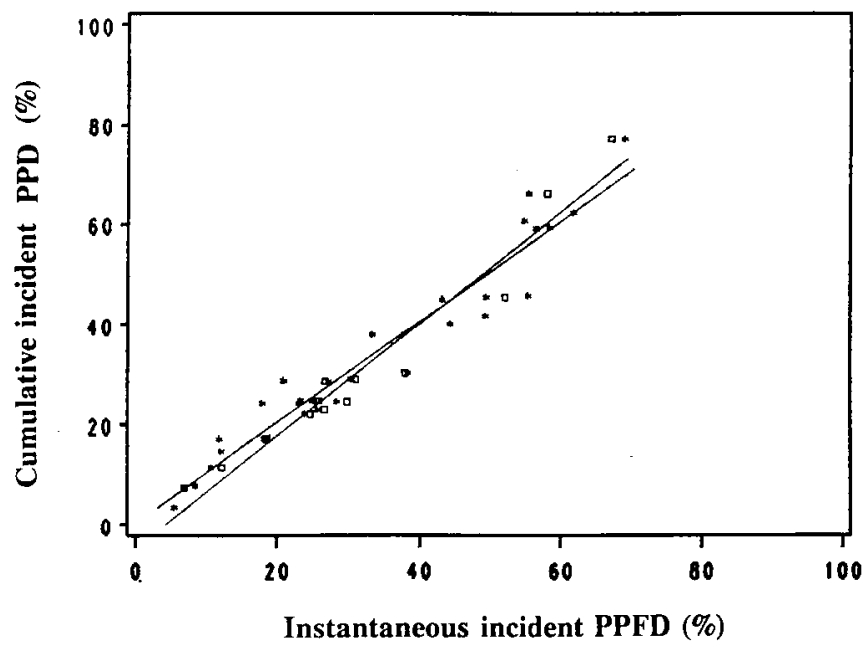

Fig. 4. Relationship between percent cumulative incident PPD and percent instantaneous incident PPFD when measurements were made with silicon photocell sensors $(*)\left[\% \mathrm{CPPD}_{\mathrm{LS}}=1+1.01\right.$ (\% INPPFD), $\left.R^{2}=0.90\right]$ and a quantum sensor $(\square) \quad\left[\% \mathrm{CPPD}_{\mathrm{LS}}=-4+1.09\right.$ (\%INPPFD), $\left.R^{2}=0.88\right]$ on 8 Aug. 1990. Models do not differ at $P<0.05$.

relatively greater discrepancy between the two sensors at extreme solar angles (early morning and late evening), but PPFD accumulations at these times were almost negligible and therefore not an appreciable source of error for total cumulative PPD measurements (data not presented). There was a one-to-one relationship (intercept $=0$ and slope $=1$ ) between the silicon photocell sensor and the quantum sensor $\left(R^{2} \geq 0.98\right)$ for overcast, hazy, or clear conditions (data not presented).

The interaction of diffuse and direct light (sunflecks) within plant canopies is a major consideration or concern associated with instantaneous light measurements in plant communities (Anderson, 1964b; Evans, 1956; Monselise, 1951). Direct light is that part of the total solar radiation that travels in a straight line from the sun to the receiving object. Diffuse light is that portion of the solar radiation reflected off clouds, and impurities in the atmosphere and may impinge on the receiving object from any direction. Direct light dominates on cloudless days, often accounting for $90 \%$ of the total radiant energy (Heinicke, 1967). The relative percentage of diffuse light increases with increasing haze or clouds, and may constitute nearly $100 \%$ of the total radiant energy for overcast conditions.

In the eastern United States, overcast and hazy conditions prevail during the growing season and result in appreciable diffuse light levels throughout the season. Thus, diffuse light should have been a major contributor to the total cumulative light for our study. Anderson (1964c) determined that diffuse light was the major contributor to total cumulative light within a temperate forest in southern England, where overcast and hazy conditions also predominate during the growing season. Therefore, it is not surprising that in the eastern United States, \%INPPFD for overcast conditions was the most appropriate predictor of \%CPPD (LS and TS), and that, for cloudless conditions, the predictive models improved with increasing haze, or diffuse light levels.

In climates with predominantly clear conditions throughout the growing season, direct light, or sunflecks, may contribute a relatively higher percentage of the total light accumulated at canopy positions throughout the season, and much attention has been devoted to the study of the importance of sun flecks within forest communities (Anderson, 1964a; Evans, 1956; Evans et 
al., 1960) and plant canopies (Lakso, 1980; Looney, 1968). On a clear day, up to $80 \%$ of the radiant energy reaching a tropical rain forest floor was from sunflecks (Evans, 1956), and within an apple canopy, light levels were very low at interior positions throughout the day when sunflecks, were excluded (Heinicke, 1966; Klein et al., 1991; Lakso and Musselman, 1976). Therefore, in areas with predominantly clear conditions during the growing season, sunflecks or direct light may constitute a larger proportion of the total available light within the canopy, and the relationship between \%INPPFD and \%CPPD could be different from our results.

Generally, instantaneous measurements from areas with predominantly clear conditions have been made under cloudless conditions (Barritt et al., 1987; Morgan et al., 1984; Patten and Proebsting, 1986). However, based on detailed cumulative light measurements within apple canopies, and observations on tree growth patterns in an area with predominantly clear sky conditions during the growing season (British Columbia, Canada), Heinicke (1963) surmised that diffuse light may be a major contributor to the total cumulative light throughout the season. The uranyl oxalate measurement technique used by Heinicke (1963) to quantify light levels within the canopy has been severely criticized (Anderson, 1964a). Uranyl oxalate solutions are most sensitive to ultraviolet and infrared radiation and may not have represented physiologically active radiation levels. Additional research should be conducted in locations with predominantly clear sky conditions to test the validity of instantaneous measurements under these conditions and to develop new models.

Regardless of the prevalent weather conditions at a given location, it often maybe necessary to make instantaneous measurements under cloudless conditions, and sunflecks should not be avoided. The importance of sun flecks in areas dominated by clear conditions has previously been discussed, and, in areas with predominantly overcast conditions, the avoidance of sunflecks could lead to the underestimation of canopy light levels because diffuse light levels would be lower due to the reduced ambient diffuse light conditions of the clear day (Lakso and Musselman, 1976). Various methods have been used to account for sunflecks within plant canopies, including the line quantum sensor (Barritt et al., 1987), and other modified sensors that measure an increased surface area (Evans et al., 1960; Marini and Barden, 1982). More precise predictions may result from instruments that measure a larger surface area than was possible with the silicon photocells in our study, particularly for clear conditions. Predictive models for instruments that measure a larger surface area than the silicon photocell may need to be developed to clarify these relationships and predictive capabilities.

In light distribution studies under forest canopies, Anderson (1964c) found that light conditions often changed dramatically (clouds, haze) before completion of a series of instantaneous measurements, resulting in significant errors. A series of instantaneous measurements within a forest community could require 5 to $10 \mathrm{~min}$ for completion, due to the logistics of making measurements over a large area and the difficulty in obtaining an ambient measurement. In our study, the series of instantaneous measurements was completed in $<90 \mathrm{sec}$ with the silicon photocell sensors; therefore, changes in ambient conditions were minimized. All measurements were made under relatively uniform light conditions, whether the conditions were overcast or cloudless. Variable conditions (partly cloudy) were avoided in this study due to the difficulty of accounting for the changing conditions. If the ambient light conditions do change signifi- cantly during a series of instantaneous measurements, the precision of predicted cumulative light levels would probably decrease, as was found with the quantum sensor measurements.

For both hazy and overcast conditions, the predictive models were equivalent for the 2 years evaluated in this study, although these years had quite different weather conditions during the growing season; it was more cloudy and rainy in 1989 than in 1990, with total cumulative late-season PPD (22 July-4 Oct.) of $2259 \mathrm{~mol} \cdot \mathrm{m}^{-2}$; in 1990 the more cloud-free weather led to a total cumulative late-season PPD of $2507 \mathrm{~mol} \cdot \mathrm{m}^{-2}$. The difference would be equivalent to about a week of additional available light over the final 10 weeks of the season in 1990. Weather conditions will, of course, vary from year-to-year for any given location, but the equivalence of the models between these 2 years strengthens the validity of these models.

The measurement and characterization of the canopy light environment are complicated processes, but we have demonstrated that instantaneous light measurements made with inexpensive silicon photocell and quantum sensors were reliable predictors of both late- and total-season cumulative light levels within an apple canopy. These results support the validity of instantaneous measurements used in previous studies and allow for the comparison of results between studies. Instantaneous measurements can be made at any time of the season, if the correct model is used. However, after canopy development is complete, the one-to-one relationship between \%INPPFD and $\% \mathrm{CPPD}_{\mathrm{LS}}$ can be used for the remainder of the growing season. Instantaneous measurements do not require the equipment and computer facilities necessary for the direct measure of cumulative light levels.

Uniformly overcast conditions would be preferable for instantaneous measurements in the eastern United States, but the average of several instantaneous measurements made under hazy conditions will also yield relatively precise estimates of \%CPPD. Assuming that instantaneous measurements are made rapidly, avoiding drastic changes in ambient light conditions, relative cumulative PPD levels (\%) can be predicted and used to estimate the cumulative total quantum energy received at any canopy position by multiplying by the total incident PPD received at that location. Incident PPD can be measured directly, or sometimes these data are available from weather monitoring stations. Thus, the amount of quantum energy received at distinct canopy positions may be estimated.

\section{Literature Cited}

Anderson, M.C. 1964a. Light relations of terrestrial plant communities and their measurement. Biol. Rev. 39:425-486.

Anderson, M.C. 1964b. Studies of the woodland climate. I. The photographic computation of light conditions. J. Ecol. 52:27-41.

Anderson, M.C. 1964c. Studies of the woodland light climate. II. Seasonal variation in the light climate. J. Ecol. 52:643-663.

Barritt, B.H., C.R. Rom, K.R. Guelich, S.R. Drake, and M.R. Dilley. 1987. Canopy position and light effects on spur, leaf, and fruit characteristics of 'Delicious' apple. HortScience 22:402-405.

Biggs, W.W., A.R. Edison, J.D. Eastin, K.W. Brown, J.W. Maranville, and M.D. Clegg. 1971. Photosynthesis light sensor and meter. Ecology 52:125-131.

Christopher, E.P. 1934. The intensity of light striking leaves of apple trees at different times of day. Proc. Amer. Soc. Hort. Sci. 32:8692.

Evans, G.C. 1956. An area survey method of investigating the distribution of light intensity in woodlands, with particular reference to sunflecks. J. Ecol. 44:391-428.

Evans, G.C., T.C. Whitmore, and Y.K. Wong. 1960. The distribution 
of light reaching the ground vegetation in a tropical rain forest. J. Ecol. 48:193-204.

Grappadelli, L.C. and D.C. Coston. 1988. A photosynthetically active radiation sensor. HortScience 23:215-217.

Heinicke, D.R. 1963. The micro-climate of fruit trees. II. Foliage and light distribution patterns in apple trees. Proc. Amer. Soc. Hort. Sci. 83:1-11.

Heinicke, D.R. 1966. The effect of natural shade on photosynthesis and light intensity in Red Delicious apple trees. Proc. Amer. Soc. Hort. Sci. 88:1-8.

Heinicke, D.R. 1967. Variations in total and diffuse radiation in relation to cloud cover and its importance on shade in tree canopies. Proc. Amer. Soc. Hort. Sci. 91:113-119.

Jackson, J.E. 1980. Light interception and utilization by orchard systems, p. 208-267. In: J. Janick (ed.). Hort. Rev. vol. 2, AVI, Westport; Conn.

Khromenko, V.V. 1972. Study of the daily course of photosynthesis in parts of apple tree crowns receiving different illumination. Soviet Plant Phys. 19:373-376.

Klein, I., T.M. DeJong, S.A. Southwick, and T.T. Muraoka. 1991. Specific leaf weight and nitrogen allocation responses to light exposure within walnut trees. HortScience 26:183-185.

Lakso, A.N. 1980. Correlations of fisheye photography to canopy structure, light climate, and biological responses to light in apple trees. J. Amer. Soc. Hort. Sci. 105:43-46.

Lakso, A.N. and R.C. Musselman. 1976. Effects of cloudiness on interior dffuse light in apple trees. J. Amer. Soc. Hort. Sci. 101:642644

Looney, N.E. 1968. Light regimes within standard size apple trees as determined spectrophotometrically. Proc. Amer. Soc. Hort. Sci. 93:16.

Marini, R.P. and J.A. Barden. 1982. Light penetration on overcast and clear days, and specific leaf weight in apple trees as affected by summer or dormant pruning. J. Amer. Soc. Hort. Sci. 107:39-43.

Marini, R.P. and M.C. Marini. 1983. Seasonal changes in specific leaf weight, net photosynthesis, and chlorophyll content of peach leaves as affected by light penetration and canopy position. J. Amer. Soc. Hort. Sci. 108:600-605.

Monselise, S.P. 1951. Light distribution in citrus trees. Bul. Res. Council of Israel 1:36-53.

Montgomery, D.C. and E.A. Peck. 1982. Introduction to linear regression analysis. Wiley, New York.

Morgan, D.C., C.J. Stanley, R. Volz, and S.I.J. Warrington. 1984. Summer pruning of 'Gala' apple: The relationships between pruning time, radiation penetration, and fruit quality. J. Amer. Soc. Hort. Sci. 109:637-642.

Patten, K.D. and E.L. Proebsting. 1986. Effect of different artificial shading times and natural light intensities on fruit quality of 'Bing' sweet cherry. J. Amer. Soc. Hort. Sci. 111:360-363.

Proctor, J.T.A., W.J. Kyle, and A.J. Davies. 1975. The penetration of global solar radiation into apple trees. J. Amer. Soc. Hort. Sci. 100:40-44.

SAS. 1985. SAS user's guide: Statistics. Version 5 (ed.). SAS Institute, Inc. Cary, N.C.

Seeley, E.J., W.C. Micke, and R. Kammereck. 1980. 'Delicious' apple fruit size and quality as influenced by radiant flux density in the immediate growing environment. J. Amer. Soc. Hort. Sci. $105: 645-647$ 